\title{
Use of granisetron transdermal system in the prevention of chemotherapy-induced nausea and vomiting: a review
}

This article was published in the following Dove Press journal:

Cancer Management and Research

16 December 2009

Number of times this article has been viewed

\author{
Albert Tuca \\ Palliative Care Hospital Team, \\ Palliative Care Department, Institut \\ Català d'Oncologia, L'Hospitalet \\ de Llobregat, Barcelona, Spain
}

\begin{abstract}
Until now only intravenous and oral formulations of $5 \mathrm{HT}_{3}$ receptor antagonists have been available. Recently a new formulation of a $5 \mathrm{HT}_{3}$ receptor antagonist, transdermal granisetron, has been developed, and approved by the FDA. Three phase I studies to evaluate its pharmacokinetic profile have shown that granisetron administered by a transdermal delivery system is absorbed by passive diffusion and maximal concentration is reached 48 hours after patch application. The patch of $52 \mathrm{~cm}^{2}$, which contains $34.3 \mathrm{mg}$ of granisetron, releases $3.3 \mathrm{mg}$ of the drug every day and maintains a stable average plasma concentration of $2.2 \mathrm{ng} / \mathrm{mL}$ over 6 days, similar to levels obtained with $2 \mathrm{mg}$ of oral granisetron, administered every day during the same period of time. Two randomized as yet unpublished clinical trials (phase II/III) have been conducted to evaluate the antiemetic efficacy of transdermal granisetron in chemotherapy-induced nausea and vomiting, in patients receiving moderately and highly emetogenic chemotherapy, compared with $2 \mathrm{mg}$ of oral granisetron. More than 800 cancer patients were included in the trials. The rate of complete control of acute emesis was $49 \%$ for the phase II trial and $60 \%$ for the phase III trial. Neither trial showed a statistically significant difference between transdermal and oral granisetron. The control of delayed emesis was observed in $46 \%$ of patients, and there were no statistically significant differences between transdermal and oral granisetron. The most common adverse effects in both trials were constipation $(<7 \%)$ and headache $(<1 \%)$; there were no statistically significant differences between transdermal and oral granisetron. These data show that transdermal granisetron is effective and safe in controlling acute emesis induced by chemotherapy with both moderate and high emetogenic potential. Efficacy and safety of transdermal granisetron are fully comparable with that of oral granisetron. More clinical trials using regimens of 2 or 3 drugs, including dexamethasone and/or aprepitant, are needed to confirm the place of transdermal granisetron in the control of chemotherapy-induced nausea and vomiting.
\end{abstract}

Keywords: cancer chemotherapy induced nausea and vomiting, selective antagonists of $5 \mathrm{HT}_{3}$ receptors, granisetron, transdemal delivery system

\section{Introduction}

Nausea and vomiting are common symptoms in patients receiving cancer chemotherapy. Twenty-five years ago, more than $70 \%$ of patients treated with cancer chemotherapy experienced nausea and vomiting. ${ }^{1,2}$ The prevalence and severity of chemotherapy-induced nausea and vomiting (CINV) are related to the specific emetic potential of chemotherapy (specific drug, dose, and treatment schedule) and to interindividual variability. At present, owing to advances in antiemetic treatment over recent decades, the incidence of CINV has been reduced to $25 \% \cdot{ }^{3-6}$ It is well known 
that this drastic change in CINV prevalence was due to the introduction to clinical practice of selective antagonists of $5 \mathrm{HT}_{3}$ and $\mathrm{NK}-1$ receptors.

It is important to recognize three different types of CINV according to its temporal pattern of onset (acute, delayed, and anticipatory), because each type of emesis requires specific therapeutic approaches. ${ }^{7,8}$ The temporal pattern of emesis owing to cisplatin administration was the first and more widely studied. Without an effective antiemetic treatment, almost all patients have nausea and vomiting during the first 2 hours after the administration of chemotherapy. Often, a reduction in the severity of emesis is observed during a period between 18 and 24 hours after cisplatin administration, and later reappears in the second and third day after administration. Based on experience of patients treated with cisplatin, the definition of different types of CINV, according with its temporal pattern of onset, is: $:^{7-10}$

- Acute CINV occurs during the first 24 hours after chemotherapy administration

- Delayed CINV occurs from at least 24 hours, or later, after chemotherapy administration.

- Anticipatory CINV occurs before drug administration, usually when nausea and vomiting have been poorly controlled in previous chemotherapy courses. This type of CINV is a conditional or learned response. Modern antiemetic treatments have reduced the incidence of anticipatory CINV. If this type of CINV does appear, the therapeutic approach is based mainly on behavioral rather than pharmacological interventions.

The combined use of different antiemetic drugs according to the temporal pattern of onset and the emetic potential of each specific chemotherapy schedule has improved drastically the incidence and severity of CINV. ${ }^{3-6}$

The therapeutic strategies to prevent and control CINV are essential to maintain nutritional status, and improve quality of life of patients receiving cancer chemotherapy. An adequate antiemetic treatment may avoid some clinical complications and the frequent need for dose reduction or delayed treatments, which obviously may influence clinical outcomes.

Until recently oral and intravenous formulations of the selective $5 \mathrm{HT}_{3}$ receptor antagonists were available, but a new formulation of a $5 \mathrm{HT}_{3}$ receptor antagonist (granisetron) by transdermal route has now been developed and approved by the US Food and Drug Administration (FDA).

\section{Pathophysiology of CINV}

Nausea and vomiting are the result of a complex reflex mechanism, which involves some neurotransmitters and its specific receptors in the central and peripheral nervous system.

The emetic process is controlled in the brain by two areas, "the vomiting center" and the chemoreceptor trigger zone (CTZ). These areas receive and process the different emetic stimuli and also generate efferent signals to the respiratory, vasomotor, and salivary centers, as well to the cranial nerves VIII and $\mathrm{X}$, which results in nausea and vomiting. Wang and Borison described in 1950 the central site of emesis regulation (vomiting center), located in the nucleus tractus solitarii of medulla oblongata. ${ }^{11}$ It is well known today that this area is a rather complex network of neural connections rather than an anatomically structured nucleus..$^{6,7,12,13}$ The CTZ is located in the area postrema in the floor of fourth ventricle, outside the blood-brain barrier. ${ }^{14-16}$ For this reason substances with emetic potential circulating in blood or cerebrospinal fluid can activate directly the CTZ. This mechanism is well demonstrated in vomiting related to administration of opioids or dopaminergic drugs. ${ }^{17,18}$

The afferent pathway of the vagus nerve, activated by different gastrointestinal stimuli, is projected onto the nucleus tractus solitarius (vomiting center) and the area postrema (CTZ), provoking the efferent emetic reflex. Dopamine, opioids, histamine, acetylcholine, substance $\mathrm{P}$, and serotonin are the main neurotransmitters involved in the stimulation of the emetic reflex by activating its specific receptors in both the central nervous system and in peripheral nerve fibers. Therefore, the pharmacologic treatment of nausea and vomiting is mainly aimed at blocking the specific receptors of some of these neurotransmitters.

Chemotherapy administration causes the release of mediators, mainly serotonin, through stimulation of the enterochromaffin cells of intestinal mucosa. These mediators bind to the specific receptors in vagal primary afferent neurons. The projection of vagal stimulus in the central nervous system (vomiting center and CTZ) triggers the emesis reflex. The most important neurotransmitters in CINV are serotonin, dopamine, and substance $\mathrm{P}$, which bind to $5 \mathrm{HT}_{3}$, dopamine-2, and NK-1 receptors, respectively. ${ }^{19,20}$ Another way of emesis activation may be the direct stimulation of CTZ by metabolites of chemotherapy or intestinal peptides circulating in the blood. This mechanism is considered possible and reasonable, but has still not fully demonstrated. ${ }^{7}$

It is well accepted that learned or conditional responses of the brain are generated in the limbic region of cerebral cortex. This brain area is probably responsible for anticipatory CINV. ${ }^{8}$ 
The cancer chemotherapy can be classified according their specific level of emetogenic risk, from a low level (less than $10 \%$ ) to a high level of risk (up to $90 \%$ ) (Table 1). ${ }^{7}$

\section{Brief review of antiemetic agents and evidence-based recommendations}

As mentioned above, the efficacy of antiemetic agents is based on their antagonist action over specific receptors of neurotransmitters involved in the vomiting reflex. These agents can be classified according to the balance between efficacy and side effects, as low or high therapeutic index.

Metoclopramide, butyrophenones, phenotiazines, cannabinoids, and olanzapine are considered agents of low therapeutic index. The selective $5 \mathrm{HT}_{3}$ antagonists, or NK-1 receptors and dexamethasone are considered agents of high therapeutic index.

Olanzapine antagonizes the $5 \mathrm{HT}_{3}$ and $\mathrm{D}_{2}$ receptors. In some phase 2 clinical trials olanzapine showed efficacy in preventing acute and delayed CINV, but no phase 3 trials have yet compared olanzapine with other antiemetic agents alone or in combination. . $^{21,22}$

Benzodiazepines have a very low antiemetic action; however their action reducing the anxiety can help in anticipatory emesis or as complementary treatment with other antiemetic agents. ${ }^{23,24}$
Metoclopramide at the usual therapeutic doses, butyrophenones, phenotiazines, and olanzapine have an antagonist action over dopamine receptors $\left(\mathrm{D}_{2}\right)$. At present these agents are not widely used because they have a moderate antiemetic capacity and a high prevalence of side effects. Metoclopramide administered in high doses acquires the capacity to block $5 \mathrm{HT}_{3}$ receptors, which improves its efficacy but it has frequent side effects. ${ }^{7,25}$

The synthetic cannabinoids nabilone and dronabinol have antiemetic efficacy during chemotherapy with low or moderate vomiting risk. The frequent occurrence of dysphoria and postural hypotension are side effects that limit their habitual use. ${ }^{26}$

Although the antiemetic mechanism of corticosteroids is not well known, their efficacy in vomiting control during chemotherapy with low emesis risk has been widely studied and demonstrated. Most clinical experience of effective vomiting control, efficacy in delayed and acute emesis has been reported with methylprednisolone and dexamethasone. The combined use of corticosteroids with other antiemetic agents, especially with $5 \mathrm{HT}_{3}$ receptor antagonists, is highly efficacious and is superior to that when administering of this drug alone..$^{27-30}$

It is well recognized that selective $5 \mathrm{HT}_{3}$ receptor antagonists (ondansetron, granisetron, dolasetron, tropisetron, palonosetron) are the most efficacious antiemetic agents in CINV. Ways of improving tolerance to chemotherapy

Table I Emesis risk level of antineoplastic drugs

\begin{tabular}{|c|c|c|c|}
\hline Level I (<10\%) & Level 2 (10\%-30\%) & Level 3 (31\%-90\%) & Level 4 (>90\%) \\
\hline Bleomicin & Bortezimib & Carboplatin & Carmustine \\
\hline Busulfan & Cetuximab & Cyclophoshamide & Cisplatin \\
\hline Vinbalstine & Cytarabine & $\left(<1.5 \mathrm{~g} / \mathrm{m}^{2}\right)$ & Cyclophosphamide \\
\hline Vinorelbine & $\left(<100 \mathrm{mg} / \mathrm{m}^{2}\right)$ & Cytarabine & $\left(>1.5 \mathrm{~g} / \mathrm{m}^{2}\right)$ \\
\hline Fludrabine & Docetaxel & Daunorubicin & Dacarbazine \\
\hline Cladribine & Etoposide & Doxorubicin & Mechlorethamine \\
\hline \multirow[t]{12}{*}{ Bevacizumab } & Flouracil & Epirubicin & Streptozocin \\
\hline & Gemcitabine & Idarubicin & \\
\hline & Ixabepilone & Ifosfamide & \\
\hline & Lapatinib & Irinotecan & \\
\hline & Methotrexate & Oxaliplatin & \\
\hline & Mitomicyn & & \\
\hline & Mitoxantrone & & \\
\hline & Paclitaxel & & \\
\hline & Pemetrexed & & \\
\hline & Temsirolimus & & \\
\hline & Topotecan & & \\
\hline & Tastuzumab & & \\
\hline
\end{tabular}


using $5 \mathrm{HT}_{3}$ receptors have seen drastic changes since their introduction to clinical practice during the last decade of the 20th century. A large number of controlled clinical trials and meta-analyses have confirmed the superiority of selective $5 \mathrm{HT}_{3}$ receptor antagonists over other antiemetic agents, and demonstrated no clinically relevant differences between drugs of this therapeutic group. ${ }^{31-33}$ Clinical trials confirmed fully the efficacy of selective $5 \mathrm{HT}_{3}$ receptor antagonists in prevention and control of acute emesis, but they showed only a modest action in control of delayed emesis. ${ }^{34}$

Palonosetron is a new $5 \mathrm{HT}_{3}$ receptor antagonist, recently introduced into clinical practice, which shows a longer half-life (40 hours) and greater affinity for $5 \mathrm{HT}_{3}$ receptors than other drugs of this group. ${ }^{35,36}$ Clinical trials comparing palonosetron with ondansetron or dolasetron, in moderately emetogenic chemotherapy, showed a statistically significant improvement in complete antiemetic response rate, for acute and delayed phase emesis in those patients who received palonosetron. ${ }^{37,38}$ Clinical trials comparing palonosetron and ondansetron in highly emetogenic chemotherapy did not show differences in rate of complete antiemetic response for the acute phase. However, some trends of superiority were observed in secondary end-points, such as a significantly longer time until the first emetic episode, and also showed a statistically significant improvement for the delayed phase in a subgroup of patients who received concomitant treatment with dexamethasone. ${ }^{39,40}$ The efficacy of palonosetron in patients who have not responded to previous antiemetic treatment, in moderately or highly emetogenic chemotherapy, has been studied in a phase II clinical trial, according to different age subgroups (elderly and nonelderly patients). This clinical trial showed a high, complete antiemetic response rate with a single dose of palonosetron, irrespective of patient age. ${ }^{41} \mathrm{~A}$ recent, large phase III clinical trial which included 1114 patients receiving highly emetogenic chemotherapy, showed that palonosetron and dexamethasone are noninferior to granisetron and dexamethasone in antiemetic control of acute phase emesis, and better than granisetron and dexamethasone in the delayed phase. ${ }^{42}$

Aprepitant was the first antagonist of the NK-1 receptor approved by the FDA and was introduced into clinical practice in 2003. In controlled clinical trials with chemotherapy of moderate or high emesis potential, combined treatment with aprepitant, $5 \mathrm{HT}_{3}$ receptor antagonists, and dexamethasone showed more efficacy than $5 \mathrm{HT}_{3}$ receptor antagonists and dexamethasone alone. These clinical trials also demonstrated that the use of aprepitant and dexamethasone between the second and fifth day was superior to dexamethasone alone for control of delayed emesis. ${ }^{4,43-47}$ An open-label, phase II study $(n=58)$ which evaluated the efficacy and safety of the triple therapy with palonosetron, dexamethasone, and aprepitant for prophylaxis of CINV in highly and moderately emetogenic chemotherapy, showed a complete antiemetic response in more than $87 \%$ in acute phase and more than $77 \%$ in delayed phase emesis. ${ }^{48}$ Phase III clinical trials are needed for confirm the place of palonosetron in such a 3-drug regimen according to its efficacy and safety compared with the older $5 \mathrm{HT}_{3}$ antagonist.

The general recommendations for managing CINV according to the majority of scientific cancer associations, from the best available clinical evidence (level I, randomized clinical trials) are: $: 6,34,49$

- Chemotherapy with low emetic risk: Use dexamethasone if it is considered appropriate.

- Chemotherapy with moderate emetic risk: Use a 2-drug regimen combining a $5 \mathrm{HT}_{3}$ receptor antagonist and dexamethasone to prevent acute emesis and either one of these drugs to prevent delayed emesis.

- Chemotherapy with high emetic risk: Use a 3-drug regimen combining a $5 \mathrm{HT}_{3}$ receptor antagonist, dexamethasone, and aprepitant to prevent acute emesis, and a 2-drug regimen combining aprepitant and dexamethasone for delayed emesis.

\section{Transdermal granisetron}

Granisetron is chemically designated as 1-methyl-N[(1R,3r,5S)-9-azabicyclo [3.3.1] non-3-yl] -1H-indazole 3-carboxamide. Its molecular weight is 348.9 (312.4 free base) and its empirical formula is $\mathrm{C}_{18} \mathrm{H}_{24} \mathrm{~N}_{4} \mathrm{O} \cdot \mathrm{HCl}$.

Granisetron is a selective of $5 \mathrm{HT}_{3}$ receptor antagonist without relevant affinity to other serotonin receptors. This agent does not show affinity for $\alpha$-adrenergic, $\beta$-adrenergic, dopamine, histamine, or opioid receptors. The antiemetic activity of granisetron, as with other selective $5 \mathrm{HT}_{3}$ receptor antagonists, is centered on blockage of specific receptors in terminal vagal fibers and in the CTZ. The most common adverse effects, similar to those other drugs of this pharmacologic group, are headache, constipation, and asthenia.

Until recently granisetron has been available only for intravenous and oral administration. A large number of clinical trials have demonstrated the high efficacy of granisetron for control of CINV, with no relevant differences from the other classic selective $5 \mathrm{HT}_{3}$ receptor antagonists. 
Recently, a transdermal patch of granisetron has been developed, which has been approved by the FDA for prevention and control of CINV.

\section{Pharmacokinetics of transdermal granisetron \\ Absorption and skin tolerability}

Three phase I studies have evaluated the pharmacokinetic profile and skin tolerability of the granisetron transdermal delivery system. The first phase I study was conducted in Germany in 2003. Twelve healthy subjects between 18 and 40 years of age were enrolled. Two patches were applied to all patients, a granisetron transdermal patch and a placebo patch, and were removed after 6 days of treatment (120 hours). The granisetron patch had a total area of $15 \mathrm{~cm}^{2}$ with a granisetron dose of $660 \mu \mathrm{g} / \mathrm{cm}^{2}$. The plasma levels of granisetron were quantified every 24 hours during 7 days. Physical examination, routine laboratory determinations, electrocardiogram, dermal tolerability, and patch adhesiveness were also recorded. Pharmacokinetic parameters were quantified in 11 subjects. The maximum plasma concentration $\left(\mathrm{C}_{\max }\right)$ obtained in any subject was $5.2 \mathrm{ng} / \mathrm{mL}$. The mean maximum concentration values were $1.5 \mathrm{ng} / \mathrm{mL}$ and the median peak time of concentration $\left(\mathrm{t}_{\max }\right)$ was 48 hours. The steady-state plasma concentration was reached between 24 and 30 hours after patch application. The plasma concentrations were stable during more than 5 days of treatment. The mean area-under-the-curve (AUC) concentration was $114 \mathrm{ng} \cdot \mathrm{h} / \mathrm{mL}$. The placebo patch was applied only to compare adhesiveness and dermal tolerability with those of the granisetron patch. A few subjects in both groups presented erythema and a small area of patch detachment was observed in fewer than $10 \%$ of cases. ${ }^{50}$

A second phase I pharmacokinetic study in conducted 2005 evaluated 3 different doses of granisetron transdermal patch and compared them with $2 \mathrm{mg}$ of oral granisetron during 5 days of treatment. Twelve healthy volunteers between 18 and 45 years were enrolled. The subjects were randomized in 4 treatment groups: once-daily dose of $2 \mathrm{mg}$ oral granisetron during 5 days and patches of $52 \mathrm{~cm}^{2}, 33 \mathrm{~cm}^{2}$, $15 \mathrm{~cm}^{2}$, containing $34.3 \mathrm{mg}, 21.8$, and $9.9 \mathrm{mg}$ of granisetron respectively, applied during 5 days. All 12 subjects completed the study. The mean of $\mathrm{C}_{\max }$ in the oral granisetron arm was 5.25 and $5.50 \mathrm{ng} / \mathrm{mL}$ in the first and fifth day respectively. The average plasma concentration $\left(\mathrm{C}_{\text {avg }}\right)$ was 2.14 and $2.6 \mathrm{ng} / \mathrm{mL}$ in the oral granisetron arm in the first and fifth day, respectively. The average plasma concentration $\left(\mathrm{C}_{\text {avg }}\right)$ for granisetron patches of 15,33 , and $52 \mathrm{~cm}^{2}$ was
$0.68,1.24$, and $2.23 \mathrm{ng} / \mathrm{mL}$, respectively. The $\left.\operatorname{AUC}_{(0 \rightarrow \infty}\right)$ with $52 \mathrm{~cm}^{2}$ granisetron patch was $420 \mathrm{ng} \cdot \mathrm{h} / \mathrm{mL}$. $\mathrm{T}_{\max }$ in the 3 different dosages of transdermal granisetron was achieved at 48 hours and the plasma levels were stable during the 5 days of treatment. Skin tolerability was assessed as acceptable for all subjects in the three different patch doses. Plasma protein binding was approximately $65 \%$. Granisetron was distributed freely between plasma and red blood cells. The stratified analysis showed no differences in granisetron clearance owing to age, gender, weight, or renal function..$^{51,52}$

The third study was a phase I study, double-blind, randomized, and placebo-controlled to evaluate skin irritation and the sensitization potential related with granisetron administered by a transdermal delivery system. Two hundred and twelve subjects aged between 19 and 63 years were enrolled in this study. This trial compared a granisetron patch of $52 \mathrm{~cm}^{2}$ and a placebo patch, both applied for different periods of exposure (30 minutes and 24,48 , and 72 hours, and 8,15 , and 22 days). To assess dermal tolerability a dermal response grading scale was used, divided into 5 points: 0 , no reaction; 1 , slight erythema; 2 , moderate erythema; 3 , severe erythema or erythema with edema; 4, erythema with vesicles or erosion. Patch adhesion was also evaluated systematically every 48 hours during the time of transdermal treatment. Slight or moderate skin reactions, 8 days after patch application, were higher for the placebo group (22.4\%) than the transdermal granisetron group (13.5\%). Allergic contact reaction was observed in only 1 subject of the transdermal granisetron group $(0.5 \%)$. No sensitization reactions were observed with the placebo patch. Adherence to greater than $90 \%$ of patch surface, 8 days after patch application, was observed in 59\% of granisetron group and in $69 \%$ of placebo group. Pharmacokinetic parameters were quantified in 24 granisetron subjects. Mean $\mathrm{C}_{\max }$ was $4.0 \mathrm{ng} / \mathrm{mL}$ for women and $2.16 \mathrm{ng} / \mathrm{mL}$ for men. Mean $\mathrm{C}_{\text {avg }}$ was 1.53 for men and $3.2 \mathrm{ng} / \mathrm{mL}$ for women. ${ }^{54}$

In summary, the main overall conclusions of these pharmacokinetics studies are: granisetron administered by the transdermal delivery system was absorbed by passive diffusion; maximal concentration was reached 48 hours after patch application; plasma levels were stable for at least 6 days; a patch of $52 \mathrm{~cm}^{2}$ delivered $3.3 \mathrm{mg} /$ day of granisetron, and maintained a $\mathrm{C}_{\text {avg }}$ of $2.2 \mathrm{ng} / \mathrm{mL}$ over 6 days, similar to that obtained with $2 \mathrm{mg}$ of oral granisetron administered every day during the same period of time; no dose adjustment was needed owing to age or renal function (Table 2); and when the patch was removed, after 6 days of treatment, the plasma concentration decreased slowly over approximately 72 hours until it became undetectable (Figure 1). ${ }^{50-54}$ 
Table 2 Pharmacokinetics parameters of oral and transdermal granisetron ${ }^{49,50,61}$

\begin{tabular}{llll}
\hline Mean & \multicolumn{2}{l}{$\begin{array}{l}\text { Granisetron } \mathbf{2} \mathbf{~ m g} \text { oral } \\
\text { daily }\end{array}$} & $\begin{array}{l}\text { Granisetron } \\
\text { patch } \mathbf{5 2} \mathbf{~ c m}^{2}\end{array}$ \\
\cline { 2 - 3 } & Day I & Day 5 & \\
\hline $\mathrm{C}_{\max } \mathrm{ng} / \mathrm{mL}$ & 5.2 & 5.5 & $4.0-2.2$ \\
$\mathrm{t}_{\max }($ hours $)$ & 1.5 & 2.0 & 48 \\
$\mathrm{C}_{\text {avg }}(\mathrm{ng} / \mathrm{mL})$ & 2.14 & 2.6 & 2.23 \\
$\mathrm{AUC}\left({ }_{0 \rightarrow \infty}\right) \mathrm{ng} \cdot \mathrm{h} / \mathrm{mL}$ & 65 & 98 & 420 \\
$\mathrm{t}_{1 / 2}$ (hours) & 6.4 & 7.9 & 35.9 \\
\hline
\end{tabular}

Abbreviations: $C_{\text {max }}$, maximal mean concentration; $t_{\text {max }}$, peak of maximal concentration; $\mathrm{C}_{\text {avg }}$, average concentration; $\mathrm{AUC}$, area under the curve concentration; $t_{1 / 2}$, half-life.

\section{Metabolism and excretion}

Metabolism of granisetron involves N-demethylation and aromatic ring oxidation, followed by conjugation with glucoronide sulphate. In vitro studies have shown that ketoconazol inhibits the metabolism of granisetron, which suggests a metabolism mediated partly by cytochrome P450 3A. Animal experimentation studies suggest that some of the metabolites have antagonist activity over $5 \mathrm{HT}_{3}$ receptors. Granisetron clearance is predominantly hepatic. Less than $20 \%$ of dose administered intravenously is excreted unchanged in urine. The rest of the dose administered is excreted $49 \%$ by the urine and $34 \%$ by the feces as metabolites, mainly 7-hydroxi-granisetron. For this reason dose adjustment in renal failure is considered unnecessary. ${ }^{54,55}$

All these data correspond to previous experimental studies of parenteral or oral granisetron. Although there are no specific data on the metabolism of this drug administered transdermally, it is reasonable to believe that metabolic pathways do not differ between different routes of administration.

\section{Clinical studies with transdermal granisetron}

Two clinical studies have evaluated the efficacy and safety of the transdermal granisetron patch in CINV.

The first was a double-blind, double-dummy, randomized, multicenter, phase II study, comparing efficacy, safety, and tolerability of the granisetron patch and oral granisetron in CINV, following a single-day administration of moderately emetogenic chemotherapy. The study was conducted at 21 centers in Germany and included 210 cancer patients with a randomization ratio of 1:1. The granisetron patch group was treated 24 hours after chemotherapy administration, with a $52 \mathrm{~cm}^{2}$ patch containing $34.3 \mathrm{mg}$ of drug, followed by a placebo capsule. The control group was treated with a placebo patch followed by a $2 \mathrm{mg}$ granisetron capsule. Rescue antiemetic medications, such as dexamethasone $8 \mathrm{mg}$ or an extra dose of granisetron, were allowed if the patients had severe nausea-vomiting. The number of emetic episodes and the severity of nausea, assessed by means a 4-point scale (no nausea, mild, moderate, and severe nausea), were recorded daily. The patients also recorded the use of rescue medications, and their satisfaction related specifically to nausea and vomiting control, using a $100 \mathrm{~mm}$ visual analogue scale (VAS). The primary endpoint of this study was to determine the proportion of patients achieving total control of CINV (no emetic episode, no nausea, and no rescue medication) or a complete control of CINV (no emetic episodes, no more than mild nausea, and no use of rescue medication). The secondary endpoints were the proportion of patients achieving a complete response or complete control during acute phase (first 24 hours) and delayed phase, and also during the overall trial period (120 hours). Total control and complete control were achieved by $43.7 \%$ and $48.3 \%$ of patients, respectively, during acute phase in the transdermal granisteron arm, compared with $52.4 \%$ and $59.5 \%$ in the oral granisetron arm (not statistically significant). Total control and complete control were achieved by $32.2 \%$ and $42.5 \%$ of patients, respectively, during delayed phase in the granisteron patch arm compared with $29.8 \%$ and $40.5 \%$ in the oral granisetron arm (not statistically significant). There were no statistically significant differences in severity of nausea-vomiting, number of emetic episodes, and patient satisfaction between the two trial groups (Table 3). Only 5 patients showed a patch adhesion failure, 1 in the granistetron patch group and 4 in control group. Side adverse events (SAE) were experienced by $30.7 \%$ of granisetron patch patients compared with $18.8 \%$ of oral granisetron patients. However, the proportion of adverse events that were considered related to trial treatment was higher in the control group than in the transdermal granisetron group ( $9.4 \%$ versus $4.5 \%)$. The most common SAE recorded was headache $(3.4 \%$ in granisetron patch group, $4.7 \%$ in control group). Treatment-related deaths or severe SAE were not observed, and the overall evaluation of SAE did not show any relevant differences between both groups. ${ }^{54-57}$

The second study was a randomized, active control, double-blind, double-dummy, parallel-group, phase III, multicenter, multinational trial to assess efficacy, tolerability, and safety of transdermal granisetron compared with oral granisetron in CINV associated with moderately and high multiday chemotherapy. A total of 641 cancer patients were included from 60 centers in 9 countries. The transdermal 


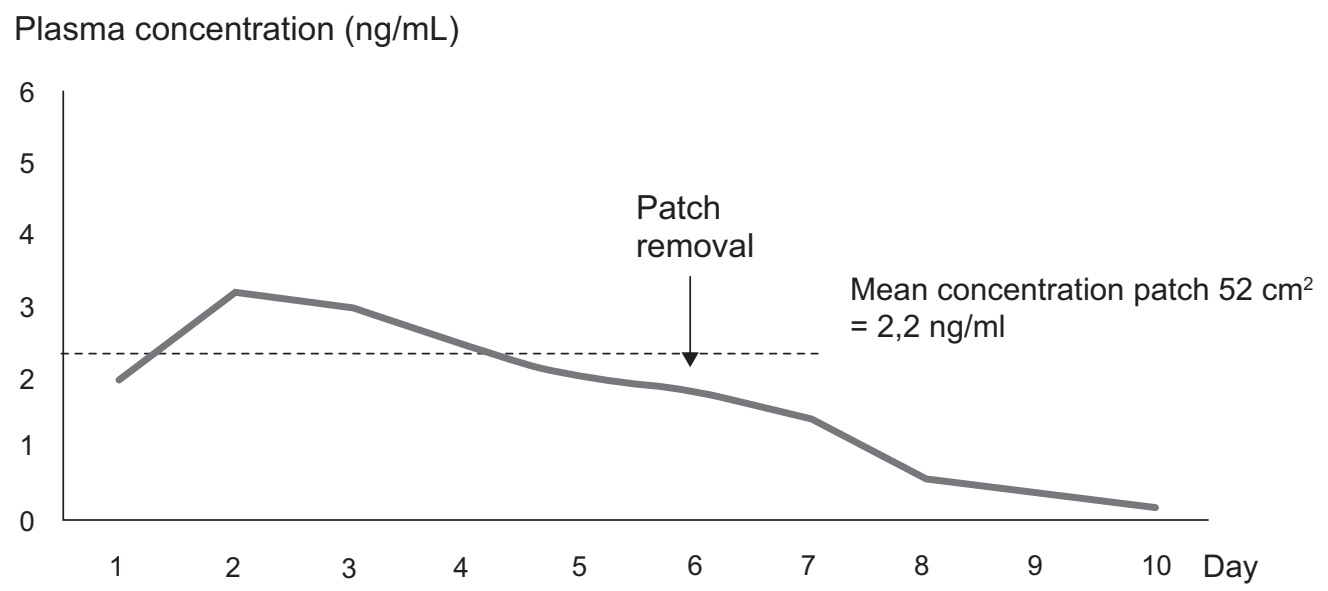

Figure I Plasma concentration of granisetron after application of the transdermal patch of $52 \mathrm{~cm}^{2}$ for 6 days of treatment. Based on study $392 \mathrm{MD} / \mathrm{I} \mathrm{I/C.49}$

granisetron group included 318 patients, who were treated with a $52 \mathrm{~cm}^{2}$ patch containing $34.3 \mathrm{mg}$ of drug, applied 24 to 48 hours before chemotherapy (which was removed on the seventh day) and associated with a placebo capsule administered 1 hour before chemotherapy every day and only during the days of chemotherapy administration. The control group included 323 patients, who were treated with a placebo patch, applied 24 to 48 hours before start of chemotherapy (removed on the seventh day) with $2 \mathrm{mg}$ granisetron capsule 1 hour prior chemotherapy every day during the days of chemotherapy. Unlike the previous phase III clinical trial, the concomitant use of corticosteroids was permitted as a part of chemotherapy regimen. More than $40 \%$ of patients in both treatment groups had metastatic disease, $30 \%$ of whom had been treated previously with chemotherapy and $20 \%$ of whom a had history of prior radiotherapy. More than $70 \%$ of patients received a 3-day chemotherapy regimen, which included cisplatin, oxaliplatin, carboplatin, or topotecan. It was considered that most of patients had regimens of combined chemotherapy with high emetogenic risk. The primary endpoint was to determine the proportion of patients achieving complete control of emesis defined as no emetic episodes, no more than mild nausea, and no use of rescue medication. The complete control of emesis in acute phase was achieved in $60.2 \%$ of patients treated with transdermal granisetron compared with $64.8 \%$ of those treated with oral granisetron; there were no statistically significant differences (Table 3). A stratified analysis was done according to sex, chemotherapy regimen (cisplatin and no cisplatin, use or no use of corticosteroids), duration of chemotherapy, and prior chemotherapy treatments. There were no statistically significant differences between these stratified groups in the rate of complete control of emesis in the acute phase. The use of rescue medication differed according to the duration of chemotherapy treatment. In chemotherapy regimens of 4 or 5 days, the use of rescue medication was higher with transdermal granisteron than with oral granisetron. In patients treated with chemotherapy regimens of 3 days the use of rescue medication did not differ between transdermal and oral granisetron groups. There were no significant differences between both groups in patient global satisfaction assessed by means VAS. Constipation was the more common SAE, occurring in $6.6 \%$ of patients treated with the granisetron patch compared with to $3.1 \%$ in the oral granisetron group. Headache related to granisetron use was observed in $0.3 \%$ of transdermal patients versus $2.5 \%$ of oral patients. Asthenia, dyspepsia, and abdominal pain were observed in less to $3 \%$ of patients in both groups. Serious SAEs potentially related to granisetron were reported in 5 cases $(0.8 \%), 1$ patient in the transdermal group (severe constipation) and in 4 patients in the oral group ( 3 with QTc prolongation and 1 with megacolon). Fifteen patients (2.3\%) died during the study period, 7 in transdermal group and 8 in oral group. Only one of these deaths, caused by megacolon in the oral group, was considered to be potentially related to granisetron. Twelve patients $(1.9 \%)$ withdrew from the study treatment owing to SAEs, 6 in each trial arm. Twothirds of patients showed a patch adhesion of greater than $90 \%$ of its surface during the trial period. ${ }^{54,58}$

\section{Discussion}

The pharmacokinetic parameters of granisetron transdermal delivery system have been recently published, ${ }^{59}$ and data on phase II-III clinical trials are still unpublished. The information included herein on clinical trials is derived from scientific documents provided by the pharmaceutical company that has 
Table 3 Rate of acute emesis control and related-treatment side adverse effects in controlled clinical trials ${ }^{56,59,60}$

\begin{tabular}{|c|c|c|c|}
\hline & & Transdermal granisetron & Oral granisetron \\
\hline \multirow[t]{4}{*}{ Phase II $(\mathrm{N}=210)$} & Complete control $^{a}$ & $48.3 \%$ & $59.5 \%$ \\
\hline & Related-treatment SAE & $4.5 \%$ & $9.4 \%$ \\
\hline & Constipation & $\mathrm{nr}$ & $\mathrm{nr}$ \\
\hline & Headache & $3.4 \%$ & $4.7 \%$ \\
\hline \multirow[t]{4}{*}{ Phase III $(\mathrm{N}=64 \mathrm{I})$} & Complete control & $60.2 \%$ & $64.8 \%$ \\
\hline & Related-treatment SAE & $7.9 \%$ & $5.6 \%$ \\
\hline & Constipation & $6.6 \%$ & $3.1 \%$ \\
\hline & Headache & $0.3 \%$ & $2.5 \%$ \\
\hline
\end{tabular}

Note: No statistically significant differences in all items in both trials.

${ }^{a}$ Complete control: no more than mild nausea, no vomiting, no rescue medication.

Abbreviations: $n r$, not reported in available documentation; SAE, side adverse effects.

developed this new route of administration of granisetron, most of which are available on the Internet. ${ }^{54,56-58}$

The pharmaconkinetic studies in healthy volunteers demonstrated that plasma concentrations of granisetron delivered by the transdermal system were similar to those obtained with oral granisetron. $\mathrm{C}_{\text {avg }}$ levels were greater the $2 \mathrm{ng} / \mathrm{mL}$ and were stable over more than 6 days in both treatments (oral administration every day or continuous transdermal delivery). $T_{\max }$ was reached later with the granisetron patch (48 hours) compared with oral granisetron (1.5 hours on first day). Despite this slow absorption by passive diffusion, a therapeutic level was reached after 24 hours of patch application. In a third pharmacokinetic study, the $\mathrm{C}_{\max }$ obtained in women was higher than that observed in men. This difference did not affect $\mathrm{C}_{\text {avg }}$, which reached the therapeutic level in both genders for more than 6 days. ${ }^{55}$ The plasma concentration of granisetron decreases 24 to 48 hours after patch removal, and becomes undetectable in a few days. According to this pharmacokinetic profile it is possible to maintain a stable plasma concentration at therapeutic levels during 5 days if the patch is applied 24 hours before the start of chemotherapy and is removed on sixth day.

According to available literature, the usual rate of emesis control in chemotherapy with moderate or high emetic potential using $5-\mathrm{HT}_{3}$ receptor antagonists is between $40 \%$ and $86 \% .{ }^{59-64}$ The higher rates of emesis control in moderately emetogenic chemotherapy are achieved with 2-drug regimens combining 5- $\mathrm{HT}_{3}$ antagonists and dexamethasone $(75 \%$ in acute emesis and $92 \%$ in delayed emesis). ${ }^{6,59,60}$ In highly emetogenic chemotherapy, the higher rates of emesis control are achieved with 3-drug regimens combining $5-\mathrm{HT}_{3}$ antagonists, dexamethasone, and aprepitant
( $83 \%$ to $93 \%$ in acute emesis and $79 \%$ to $76 \%$ in delayed emesis) ${ }^{6,27,28,64,68-70}$ The clinical trials that included specifically granisetron combined with dexamethasone reported a rate of complete emesis control in $60 \%$ and $86 \%$ of patients, higher than the $70 \%$ with intravenous granisetron, ${ }^{61}$ and $60 \%$ to $86 \%$ with oral granisetron. ${ }^{62-64} \mathrm{~A}$ recent phase III clinical trial comparing palonosetron plus dexamethasone with intravenous granisetron plus dexamethasone in highly emetogenic chemotherapy reported a $73.3 \%$ complete response with granisetron plus dexamethasone. ${ }^{42}$

It is not possible compare these findings (2- or 3-drug regimens) with the results of transdermal granisetron trials, because only granisetron monotherapy was used.

We need to review older clinical trials evaluating the efficacy of $5-\mathrm{HT}_{3}$ antagonists administered alone without the use of corticosteroids for control of CINV. Several literature reviews on the use of $5-\mathrm{HT}_{3}$ receptor antagonists used in monotherapy, for control of CINV in chemotherapy with moderate emetic potential, have reported an emetic control rate of $40 \%$ to $60 \%{ }^{6,59,60,66}$ Some older phase II/III clinical trials, which evaluated the efficacy of granisetron alone, without corticosteroids, in highly emetogenic chemotherapy, reported a complete control of emesis (no emetic episodes, no more than mild nausea, no rescue medication) in 52\% to $49 \%$ of patients, and a complete response (no emetic episodes, no nausea, no medication rescue) in $36 \%$ to $32 \%$ of patients. ${ }^{65,66}$

In the first phase II clinical trial comparing transdermal granisetron patch with oral granisetron, complete antiemetic control in acute phase was achieved in $48.3 \%$ and $59.5 \%$ of patients, respectively. ${ }^{54,56,57}$ The control of CINV in half the patients treated with transdermal granisetron is comparable 
with previous data on oral granisetron alone $(52 \%){ }^{66}$ This rate of emesis control is also comparable with that of other selective $5-\mathrm{HT}_{3}$ antagonists used in monotherapy, (40\% to $60 \%),{ }^{59,60,66}$ taking into account that there are no relevant differences in clinical efficacy between classic $5-\mathrm{HT}_{3}$ antagonists assessed by meta-analyses. ${ }^{32,33,67}$

A large phase III clinical trial on transdermal granisetron has been conducted. ${ }^{58}$ The main differences between this study and previous phase II clinical trials ${ }^{57}$ were the inclusion of patients receiving high emetogenic potential chemotherapy, and the possibility of adding corticosteroids as part of the chemotherapy regimen. A complete control of emesis in the acute phase was achieved in $60.2 \%$ of patients treated with transdermal granisetron, although there were no statistically significant differences compared with the control group treated with oral granisetron. Despite the inclusion of patients receiving high emetogenic chemotherapy, the rate of emesis control in this study is higher than reported in a previous phase II clinical trial in moderately emetogenic chemotherapy (49.4\%). The concomitant use of corticosteroids as part of chemotherapy in some patients could be the reason for an overall improvement of emesis control. However, a stratified analysis comparing patients who received or did not receive corticosteroids in both arms of the trial did not show any statistically significant differences.

As expected, according to the pharmacological profile of granisetron, and other $5 \mathrm{HT}_{3}$ receptor antagonists, the antiemetic efficacy which was assessed in these clinical trials $\mathrm{s}^{57,58}$ was mainly focused on acute vomiting. The emetic control in delayed phase was comparable in both arms of the two trials, $46.0 \%$ for granisetron patch versus $46.4 \%$ for oral granisetron (no statistically significant differences). A relevant finding in a phase III clinical trial is the need for more rescue medication for transdermal granisetron patients in chemotherapy regimens longer than 3 days. The pharmacokinetic data show a slight decrease in plasma concentration of granisetron from the fourth day of patch application, despite maintaining a mean concentration at therapeutic levels. A higher peak of maximal plasma concentration, by oral administration of granisetron every 24 hours, may be the reason for a lower need of rescue medication in chemotherapies longer than 3 days.

Constipation and headache are the most common SAEs for $5 \mathrm{HT}_{3}$ receptor antagonists reported in literature, and appear in around $10 \%$ of patients. ${ }^{73}$ Constipation was observed in less of $7 \%$ of patients and headache in less of $1 \%$ of patients treated with transdermal granisteron (not statistically significant compared with oral granisetron control group), and fully comparable with reported SAE rates.
Skin adhesion of the patch is very important to assure an optimal absorption of drug by passive diffusion. A rate of skin adhesion of greater than $90 \%$ of patch surface was found in most of patients, a fact confirmed also in the pharmacokinetic studies by stable mean plasma concentrations during more than 6 days. Patient satisfaction with overall control of emesis was assessed using a VAS. There were no statistically significant differences in patient satisfaction between transdermal and oral granisetron for emesis control. Opinion about the comfort of drug administered by patch and preferences of patients were not assessed in these studies because the trials were double dummy and the patch was applied in all patients.

The management of nausea and vomiting induced by radiotherapy includes measures to modify risk factors and prophylactic antiemetic medication in those treatments with high emetic potential. The usual antiemetic treatments used for this indication are the dopamine antagonists, antihistamines, anticholinergics, and $5 \mathrm{HT}_{3}$ antagonists. A recent literature review confirmed that $5 \mathrm{HT}_{3}$ antagonists, with or without corticosteroids, achieved better emesis control than other antiemetic drugs. ${ }^{71}$ Transdermal granisetron may be an effective and comfortable option to treat the emesis induced by radiotherapy. It would be reasonable and interesting to conduct controlled clinical trials comparing oral $5 \mathrm{HT}_{3}$ antagonists and transdermal granisetron with or without corticosteroids in radiation therapy with high emetic risk.

The symptomatic treatment of inoperable malignant bowel obstruction is based on rational use of analgesia, corticosteroids, and antiemetic and antisecretory drugs. Two recent systematic literature reviews, published in 2004 and 2007, recommended the use of octreotide, a synthetic analog of somatostatin, in patients with inoperable bowel obstruction. ${ }^{74,75}$ The antisecretory effect of octreotide was higher than that of other anticholinergic drugs (hyoscine). According to clinical trial data, the combination of octreotide plus dopamine antagonist significantly increased the rate of nausea and vomiting control compared with hyoscine plus dopamine antagonist. The butyrophenones and phenotiazines, haloperidol or chlorpromazine, have been the dopamine antagonists more frequently used. Most of authors do not recommend the use of metoclopramide, because its prokinetic effect may paradoxically increase colic pain. Efficacy of granisetron in control of nausea and vomiting owing to inoperable malignant bowel obstruction in advanced cancer patients has been recently reported. ${ }^{72}$ This phase II clinical trial showed excellent antiemetic control when using intravenous granisetron plus dexamethasone in more than $85 \%$ of patients with inoperable malignant bowel obstruction and previous inadequate control with antiemetic drugs. 
The use of octreotide was no allowed in this trial because it was a phase II study addressed to demonstrate efficacy of granisetron in a new indication. Phase III clinical trials are needed to compare granisetron and standard dopamine antagonists, combined with dexamtehasone and octreotide in both groups, to confirm the clinical efficacy of $5 \mathrm{HT}_{3}$ antagonists in symptomatic control of inoperable bowel obstruction. It would also be very interesting to explore by means of controlled clinical trials the antiemetic efficacy of transdermal granisetron associated with corticosteroids and octreotide in this severe complication.

The comfort of patients is highly important and must be considered. Although patient satisfaction, mainly in relation to emesis control, with transdermal administration has been shown in clinical studies to be similar to that with oral administration. The transdermal route may bring more comfort to the patient. The patch is simple to apply and is maintained throughout chemotherapy without skin problems in most patients. For these reasons transdermal treatment may reassure patients because they do not need to remember to take a pill. The substitution of intravenous administration of $5 \mathrm{HT}_{3}$ antagonists with transdermal administration can avoid one of the many venous manipulations necessary in chemotherapy, especially important in multiday treatments. In patients with swallowing disorders (such as, dysphagia, mucositis, structural changes in the oral cavity, vomiting) the transdermal delivery of granisetron may be easier and less invasive than intravenous administration. Future studies on the granisetron patch should include the assessment of quality of life using validated scales, and qualitative exploration of patient satisfaction or preference.

The overall conclusion to be drawn from the the data reviewed is that transdermal granisetron is effective and safe in controlling acute emesis induced by chemotherapy with moderate and high emetogenic potential, and its efficacy and safety are fully comparable with those of oral granisetron. However, more phase III clinical trials are needed to confirm the place granisetron transdermal delivery systems for the control of CINV. In order to improve our knowledge about transdermal granisetron these proposed controlled clinical trials must be focused on the following areas:

- Comparison of granisetron transdermal delivery system with other selective $5 \mathrm{HT}_{3}$ receptor antagonists, including palonosetron, in 2- or 3-drug antiemetic regimens (with dexamethasone or with dexamethasone plus aprepitant), according to the different levels of chemotherapy emetic risk, for the control of acute and delayed CINV.

- Comparison of granisetron transdermal delivery system with other selective of $5 \mathrm{HT}_{3}$ receptor antagonists, in radiotherapy-induced nausea-vomiting or in symptomatic control of inoperable malignant bowel obstruction.

- Quality of life (validated tools), and patient satisfaction and/or preference related specifically to transdermal administration compared with oral or intravenous of $5 \mathrm{HT}_{3}$ antagonists.

\section{Disclosure}

The author has no involvement in the pharmaceutical company that has developed the granisetron transdermal delivery system, nor has he received any funding to support the preparation of this paper, which is based only on available literature. The author declares no involvement that can be construed as a conflict of interest.

\section{References}

1. Morran C, Smith DC, Anderson DA, McArdle CS. Incidence of nausea and vomiting with cytotoxic chemotherapy: a prospective randomised trial of antiemetics. Br Med J. 1979;1:1323-1324.

2. Coates A, Dillenbeck CF, McNeil DR, et al. On the receiving end - II. Linear analogue self-assessment (LASA) in evaluation of aspects of the quality of life of cancer patients receiving therapy. Eur J Cancer Clin Oncol. 1983;19:1633-1637.

3. Griffin AM, Butow PN, Coates AS, et al. On the receiving end. V: Patient perceptions of the side effects of cancer chemotherapy in 1993. Ann Oncol. 1996;7:189-195.

4. Hesketh PJ, Grunberg SM, Gralla RJ, et al; Aprepitant Protocol 052 Study Group. The oral neurokinin-1 antagonist aprepitant for the prevention of chemotherapy-induced nausea and vomiting: a multinational, randomized, double-blind, placebo-controlled trial in patients receiving high-dose cisplatin - the Aprepitant Protocol 052 Study Group. J Clin Oncol. 2003;21:4112-4119.

5. Poli-Bigelli S, Rodrigues-Pereira J, Carides AD, et al; Aprepitant Protocol 054 Study Group. Addition of the neurokinin 1 receptor antagonist aprepitant to standard antiemetic therapy improves control of chemotherapyinduced nausea and vomiting. Results from a randomized, double-blind, placebo-controlled trial in Latin America. Cancer. 2003;97:3090-3098.

6. Naeim A, Dy SM, Lorenz KA, Sanati H, Walling A, Asch SM. Evidencebased recommendations for cancer nausea and vomiting. J Clin Oncol. 2008;26:3903-3910.

7. Hesketh PJ. Chemotherapy-induced nausea and vomiting. $N$ Engl $J$ Med. 2008;358:2482-2494.

8. American Society of Health-System Pharmacist. Therapeutic guidelines on the pharmacologic management of nausea and vomiting in adult and pediatric patients receiving chemotherapy or radiation therapy or undergoing surgery. Am J Health Syst Pharm. 1998;56:729-764.

9. Kris MG, Cubeddu LX, Gralla RJ, et al. Are more antiemetic trials with a placebo necessary? Report of patient data from randomized trials of placebo antiemetics with cisplatin. Cancer. 1996;78:2193-2198.

10. Tavorath R, Hesketh PJ. Drug treatment of chemotherapy-induced delayed emesis. Drugs. 1996;52:639-648.

11. Wang SC, Borison HL. The vomiting center: a critical experimental analysis. Arch Neurol Psychiatry. 1950;63:928-941.

12. Hornby PJ. Central neurocircuitry associated with emesis. Am J Med. 2001;111(Suppl 8A):106S-112S.

13. Miller $\mathrm{AD}$, Grelot $\mathrm{S}$. Neural control of respiratory muscle activation during vomiting. In: Miller AD, Bianchi AL, Bishop BP, eds. Neural Control of the Respiratory Muscles. Boca Raton, FL: CRC Press, 1997:239-248.

14. Miller AD, Leslie RA. The area postrema and vomiting. Front Neuroendocrinol. 1994;15:301-320. 
15. Borison HL. Area postrema: chemoreceptor circumventricular organ of the medulla oblongata. Prog Neurobiol. 1989;32:351-390.

16. Higgins GA, Kilpatrick GJ, Bunce KT, Jones BJ, Tyers MB. 5-HT receptor antagonists injected into the area postrema inhibit cisplatininduced emesis in the ferret. Br J Pharmacol. 1989;97:247-255.

17. Carpenter DO, Briggs DB, Strominger N. Responses of neurons of canine area postrema to neurotransmitters and peptides. Cell Mol Neurobiol. 1983;3:113-126.

18. Carpenter DO, Briggs DB, Strominger N. Peptide-induced emesis in dogs. Behav Brain Res. 1984;11:277-281.

19. Andrews PL, Davis CJ, Bingham S, Davidson HI, Hawthorn J, Maskell L. The abdominal visceral innervation and the emetic reflex: pathways, pharmacology, and plasticity. Can J Physiol Pharmacol. 1990;68:325-345.

20. Andrews PL, Sanger GJ. Abdominal vagal afferent neurons: an important target for the treatment of gastrointestinal dysfunction. Curr Opin Pharmacol. 2002;2:650-656.

21. Navari RM, Einhorn LH, Passik SD, et al. A phase II trial of olanzapine for the prevention of chemotherapy-induced nausea and vomiting: a Hoosier Oncology Group study. Support Care Cancer. 2005;13:529-534.

22. Navari RM, Einhorn LH, Loehrer PJ Sr, et al. A phase II trial of olanzapine, dexamethasone, and palonosetron for prevention of chemotherapy-induced nausea and vomiting: a Hoosier Oncology Group study. Support Care Cancer. 2007;15:1285-1291.

23. Bowcock SJ, Stockdale AD, Bolton JA, Kang AA, Retsas S. Antiemetic prophylaxis with high dose metoclopramide or lorazepam in vomiting induced by chemotherapy. Br Med J (Clin Res Ed). 1984;288:1879-1879.

24. Laszlo J, Clark RA, Hanson DC, Tyson L, Crumpler L, Gralla R. Lorazepam in cancer patients treated with cisplatin: a drug having antiemetic, amnesic, and anxiolytic effects. J Clin Oncol. 1985;3:864-869.

25. Blower PR. The role of specific $5-\mathrm{HT}_{3}$ receptor antagonism in the control of cytostatic drug-induced emesis. Eur J Cancer. 1990;26(Suppl 1): S8-S11.

26. Tramèr MR, Carroll D, Campbell FA, Reynolds DJ, Moore RA, McQuay HJ. Cannabinoids for control of chemotherapy induced nausea and vomiting: quantitative systematic review. BMJ. 2001;323:16-21.

27. Hesketh PJ, Harvey WH, Harker WG, et al. A randomized, double-blind comparison of intravenous ondansetron alone and in combination with intravenous dexamethasone in the prevention of high-dose cisplatininduced emesis. J Clin Oncol. 1994;12:596-600.

28. The Italian Group for Antiemetic Research. Dexamethasone, granisetron, or both for the prevention of nausea and vomiting during chemotherapy for cancer. N Engl J Med. 1995;332:1-5.

29. Latreille J, Stewart D, Laberge F, et al. Dexamethasone improves the efficacy of granisetron in the first $24 \mathrm{~h}$ following high-dose cisplatin chemotherapy. Support Care Cancer. 1995;3:307-312.

30. Ioannidis JP, Hesketh PJ, Lau J. Contribution of dexamethasone to control of chemotherapy-induced nausea and vomiting: a meta-analysis of randomized evidence. J Clin Oncol. 2000;18:3409-3422.

31. Use of 5-HT $\mathrm{H}_{3}$ receptor antagonists in patients receiving moderately or highly emetogenic chemotherapy. Practice guideline report no. 12-13. Toronto: Cancer Care Ontario; 2003.

32. del Giglio A, Soares HP, Caparroz C, Castro PC. Granisetron is equivalent to ondansetron for prophylaxis of chemotherapy-induced nausea and vomiting: results of a meta-analysis of randomized controlled trials. Cancer. 2000;89:301-2308.

33. Jordan K, Hinke A, Grothey A, Schmoll HJ. Granisetron versus tropisetron for prophylaxis of acute chemotherapy-induced emesis: a pooled analysis. Support Care Cancer. 2005;13:26-31.

34. Kris MG, Hesketh PJ, Somerfield MR, et al. American Society of Clinical Oncology guideline for antiemetics in oncology: update 2006. J Clin Oncol. 2006;24:2932-2947.

35. Geling O, Eichler HG. Should 5-hydroxytryptamine-3 receptor antagonists be administered beyond 24 hours after chemotherapy to prevent delayed emesis? Systematic re-evaluation of clinical evidence and drug cost implications. J Clin Oncol. 2005;23:1289-1294.
36. Tonini G, Vincenzi B, Santini D. New drugs for chemotherapy-induced nausea and vomiting: focus on palonosetron. Expert Opin Drug Metab Toxicol. 2005;1:143-149.

37. Gralla R, Lichinitser M, Van Der Vegt S, et al. Palonosetron improves prevention of chemotherapy-induced nausea and vomiting following moderately emetogenic chemotherapy: results of a double-blind randomized phase III trial comparing single doses of palonosetron with ondansetron. Ann Oncol. 2003;14:1570-1577.

38. Eisenberg P, Figueroa-Vadillo J, Zamora R, et al. Improved prevention of moderately emetogenic chemotherapy-induced nausea and vomiting with palonosetron, a pharmacologically novel $5-\mathrm{HT}_{3}$ receptor antagonist: results of a phase III, single-dose trial versus dolasetron. Cancer. 2003;98:2473-2482.

39. Aapro MS, Grunberg SM, Manikhas GM, et al. A phase III, double-blind, randomized trial of palonosetron compared with ondansetron in preventing chemotherapy-induced nausea and vomiting following highly emetogenic chemotherapy. Ann Oncol. 2006;17: 1441-1449.

40. Aapro MS. Palonosetron as an anti-emetic and anti-nausea agent in oncology. Ther Clin Risk Manag. 2007;3:1009-1020.

41. Massa E, Astara G, Madeddu C, et al. Palonosetron plus dexamethasone effectively prevents acute and delayed chemotherapy-induced nausea and vomiting following highly or moderately emetogenic chemotherapy in pre-treated patients who have failed to respond to a previous antiemetic treatment: comparison between elderly and non-elderly patient response. Crit Rev Oncol Hematol. 2009;70(1):83-91.

42. Saito M, Aogi K, Sekine I, et al. Palonosetron plus dexamethasone versus granisetron plus dexamethasone for prevention of nausea and vomiting during chemotherapy: a double-blind, double-dummy, randomised, comparative phase III trial. Lancet Oncol. 2009;10(2):115-124.

43. Herrstedt J. Chemotherapy-induced nausea and vomiting: ESMO clinical recommendations for prophylaxis. Ann Oncol. 2007;18(Suppl 2): ii83-ii85.

44. Schmoll HJ, Aapro MS, Poli-Bigelli S, et al. Comparison of an aprepitant regimen with a multiple-day ondansetron regimen, both with dexamethasone, for antiemetic efficacy in high-dose cisplatin treatment. Ann Oncol. 2006;17:1000-1006.

45. Warr DG, Hesketh PJ, Gralla RJ, et al. Efficacy and tolerability of aprepitant for the prevention of chemotherapy-induced nausea and vomiting in patients with breast cancer after moderately emetogenic chemotherapy. J Clin Oncol. 2005;23:2822-2830.

46. de Wit R, Herrstedt J, Rapoport B, et al. The oral NK(1) antagonist, aprepitant, given with standard antiemetics provides protection against nausea and vomiting over multiple cycles of cisplatin-based chemotherapy: a combined analysis of two randomised, placebo-controlled phase III clinical trials. Eur J Cancer. 2004;40:403-410.

47. Herrstedt J, Muss HB, Warr DG, et al. Efficacy and tolerability of aprepitant for the prevention of chemotherapy-induced nausea and emesis over multiple cycles of moderately emetogenic chemotherapy. Cancer. 2005;104:1548-1555.

48. Grote T, Hajdenberg J, Cartmell A, et al. Combination therapy for chemotherapy-induced nausea and vomiting in patients receiving moderately emetogenic chemotherapy: palonosetron, dexamethasone, and aprepitant. J Support Oncol. 2006;4:403-408.

49. Roila F, Hesketh PJ, Herrstedt J. Prevention of chemotherapy- and radiotherapy-induced emesis: Results of the 2004 Perugia International Antiemetic Consensus Conference. Ann Oncol. 2006;17:20-28.

50. Clinical Study Report 392MD/4/C. Strakan Pharmacuetical Ltd. June 2003.

51. Clinical Study Report 392MD/11/C. Strakan Pharmacuetical Ltd. June 2005

52. Howell J, Smeets J, Drenth HJ, Gill D. Pharmacokinetics of a granisetron transdermal system for the treatment of chemotherapyinduced nausea and vomiting. J Oncol Pharm Pract. 2009 Mar 20. [Epub ahead of print].

53. Clinical Study Report 392MD/26/C. Strakan Pharmacuetical Ltd. June 2007. 
54. Antonopoulos MS, Caspi A. Granisetron Transdermal Delivery, Product Profiler. P T. 2008;33(10):1-27.

55. Clarke SE, Austin NE, Bloomer JC, et al. Metabolism and disposition of 14C-granisetron in rat, dog and man after intravenous and oral dosing. Xenobiotica. 1994;24:1119-1131.

56. A granisetron patch. The Medical Letter. 2008;50(1301/13032):103-104.

57. Clinical Study Report 392MD/8/C. Strakan Pharmacuetical Ltd. May 2007.

58. Clinical Study Report 392MD/15/C. Strakan Pharmacuetical Ltd. July 2006.

59. Cubeddu LX, Pendergrass K, Ryan T, et al. Efficacy of oral ondansetron, a selective antagonist of 5-HT3 receptors, in the treatment of nausea and vomiting associated with cyclophosphamide-based chemotherapies. Ondansetron Study Group. Am J Clin Oncol. 1994;17:137-146.

60. Jantunen IT, Kataja VV, Muhonen TT. An overview of randomised studies comparing 5-HT3 receptor antagonists to conventional antiemetics in the prophylaxis of acute chemotherapy-induced vomiting. Eur J Cancer. 1997;33:66-74.

61. Yonemura M, Katsumata N, Hashimoto H, et al. Randomized controlled study comparing two doses of intravenous granisetron (1 and $3 \mathrm{mg}$ ) for acute chemotherapy-induced nausea and vomiting in cancer patients: a non-inferiority trial. Jpn J Clin Oncol. 2009;39:443-448.

62. Jordan K, Grothey A, Kegel T, Fibich C, Schöbert C. Antiemetic efficacy of an oral suspension of granisetron plus dexamethasone and influence of quality of life on risk for nausea and vomiting. Onkologie. 2005;28:88-92.

63. Tan M, Xu R, Seth R. Granisetron vs dolasetron for acute chemotherapyinduced nausea and vomiting (CINV) in high and moderately high emetogenic chemotherapy: an open-label pilot study. Curr Med Res Opin. 2004;20:879-882.

64. Aapro MS, Thuerlimann B, Sessa C, De Pree C, Bernhard J, Maibach R; Swiss Group for Clinical Cancer Research. A randomized double-blind trial to compare the clinical efficacy of granisetron with metoclopramide, both combined with dexamethasone in the prophylaxis of chemotherapy-induced delayed emesis. Ann Oncol. 2003;14(2):291-297.
65. Gebbia V, Cannata G, Testa A, et al. Ondansetron versus granisetron in the prevention of chemotherapy-induced nausea and vomiting. Results of a prospective randomized trial. Cancer. 1994;74:1945-152.

66. Addelman M, Erlichman C, Fine S, Warr D, Murray C. Phase I/II trial of granisetron: a novel 5-hydroxytryptamine antagonist for the prevention of chemotherapy-induced nausea and vomiting. J Clin Oncol. 1990;8:337-341.

67. del Giglio A, Soares HP, Caparroz C, Castro PC. Granisetron is equivalent to ondansetron for prophylaxis of chemotherapy-induced nausea and vomiting: results of a meta-analysis of randomized controlled trials. Cancer. 2000;89:2301-2308.

68. Navari RM, Reinhardt RR, Gralla RJ, et al. Reduction of cisplatin-induced emesis by a selective neurokinin-1-receptor antagonist: L-754,030 Antiemetic Trials Group. N Engl J Med. 1999;340:190-195.

69. Schmoll HJ, Aapro MS, Poli-Bigelli S, et al. Comparison of an aprepitant regimen with a multiple-day ondansetron regimen, both with dexamethasone, for antiemetic efficacy in high-dose cisplatin treatment. Ann Oncol. 2006; 17:1000-1006.

70. Warr DG, Grunberg SM, Gralla RJ, et al. The oral NK(1) antagonist aprepitant for the prevention of acute and delayed chemotherapy-induced nausea and vomiting: Pooled data from 2 randomised, double-blind, placebo controlled trials. Eur J Cancer. 2005;41:1278-1285.

71. Abdelsayed GG. Management of radiation-induced nausea and vomiting. Exp Hematol. 2007;35(4 Suppl 1):34-36.

72. Tuca A, Roca R, Sala C, et al. Efficacy of granisetron in the antiemetic control of nonsurgical intestinal obstruction in advanced cancer: a phase II clinical trial. J Pain Symptom Manage. 2009;37:259-270.

73. Herrstedt J, Domberdonwsky. Anti-emetic threapy in cancer chemotherapy: current status. Basic Clin Pharmacol Toxicol. 2007;1001: 143-150.

74. Ripamonti C, Mercadante S. How to use octreotide for malignant bowel obstruction. J Support Oncol. 2004;2(4):357-364.

75. Mercadante S, Casuccio A, Mangione S. Medical treatment for inoperable malignant bowel obstruction: a qualitative systematic review. J Pain Symptom Manage. 2007;33(2):217-223.
Cancer Management and Research

\section{Publish your work in this journal}

Cancer Management and Research is an international, peer-reviewed open access journal focusing on cancer research and the optimal use of preventative and integrated treatment interventions to achieve improved outcomes, enhanced survival and quality of life for the cancer patient. The journal welcomes original research, clinical \& epidemiological

\section{Dovepress}

studies, reviews \& evaluations, guidelines, expert opinion \& commentary, case reports \& extended reports. The manuscript management system is completely online and includes a very quick and fair peerreview system, which is all easy to use. Visit http://www.dovepress.com/ testimonials.php to read real quotes from published authors. 